\title{
A Low-Temperature Micro Hotplate Gas Sensor Based on AlN Ceramic for Effective Detection of Low Concentration $\mathrm{NO}_{2}$
}

\author{
Wen-Jie Zhao ${ }^{1,2}$, Dan $\mathrm{Xu}^{3, *}$, Yin-Sheng Chen ${ }^{1}$, Xuan Wang ${ }^{2}$ and Yun-Bo Shi ${ }^{1,2}$ \\ 1 Higher educational key laboratory for Measuring \& Control Technology and Instrumentations of \\ Heilongjiang Province, Harbin University of Science and Technology, Harbin 150080, China \\ 2 State Key Laboratory Breeding Base of Dielectrics Engineering, Harbin University of Science and Technology, \\ Harbin 150080, China \\ 3 Key Laboratory of Quantum Manipulation \& Control of Heilongiiang Province, Harbin University of Science \\ and Technology, Harbin 150080, China \\ * Correspondence: xudan@hrbust.edu.cn
}

Received: 23 July 2019; Accepted: 27 August 2019; Published: 28 August 2019

\begin{abstract}
Air pollution is one of the major threats to human health. The monitoring of toxic $\mathrm{NO}_{2}$ gas in urban air emission pollution is becoming increasingly important. Thus, the development of an $\mathrm{NO}_{2}$ sensor with low power consumption, low cost, and high performance is urgent. In this paper, a planar structural micro hotplate gas sensor based on an AlN ceramic substrate with an annular $\mathrm{Pt}$ film heater was designed and prepared by micro-electro-mechanical system (MEMS) technology, in which $\mathrm{Pt} / \mathrm{Nb} / \mathrm{In}_{2} \mathrm{O}_{3}$ composite semiconductor oxide was used as the sensitive material with a molar ratio of $\mathrm{In}: \mathrm{Nb}=9: 1$. The annular thermal isolation groove was designed around the heater to reduce the power consumption and improve the thermal response rate. Furthermore, the finite element simulation analysis of the thermal isolation structure of the sensor was carried out by using ANSYS software. The results show that a low temperature of $94^{\circ} \mathrm{C}$, low power consumption of $150 \mathrm{~mW}$, and low concentration detection of 1 to $10 \mathrm{ppm} \mathrm{NO} \mathrm{N}_{2}$ were simultaneously realized for the $\mathrm{Nb}$-doped $\mathrm{In}_{2} \mathrm{O}_{3}$-based gas sensor. Our findings provide a promising strategy for the application of $\operatorname{In}_{2} \mathrm{O}_{3}$-based sensors in highly effective and low concentration $\mathrm{NO}_{2}$ detection.
\end{abstract}

Keywords: gas sensor; ceramic micro hotplate; nitrogen dioxide; simulation analysis; low concentration

\section{Introduction}

Nitrogen dioxide is not only a highly toxic and dangerous chemical gas but also an important petrochemical raw material and space propulsion fuel. It is also one of the main air pollution gases emitted by motor vehicle exhaust. It has an important impact on environmental pollution and human physical and mental health [1,2]. $\mathrm{NO}_{2}$ has strong oxidation and is easily transformed into unstable $\mathrm{NO} x$, whose concentration is greatly affected by temperature and humidity. It is an important component of acid rain and becomes a difficult point in sensor detection [3]. Compared with traditional sensors, low power consumption, low cost, and portable application are the key factors for the wide application of $\mathrm{NO}_{2}$ gas sensors [4]. At present, the detection method of the $\mathrm{NO}_{2}$ gas sensor mainly adopts an electrochemical type and semiconductor type [5,6], while the $\mathrm{NO}_{2}$ gas detection method in an atmospheric environment is chemiluminescence and differential absorption spectroscopy, with the disadvantages of a high detection cost and complex operation, which cannot meet the requirements of real-time on-line detection, thus limiting its wide application $[7,8]$. In the case of traditional sensor 
monitoring, improving sensor manufacturing performance, signal detection level, and data processing model are the most promising ways to achieve low cost and fast, portable, and effective detection $[9,10]$.

Sensors based on metal oxide semiconductors (MOS) have been widely investigated for $\mathrm{NO}_{2}$ detection, such as $\mathrm{SnO}_{2}, \mathrm{TiO}_{2}, \mathrm{ZnO}, \mathrm{WO}_{3}$, and $\mathrm{In}_{2} \mathrm{O}_{3}$, etc. [11-13], which can effectively improve gas sensitivity characteristics through hybridization and modification with the advantages of a simple method, low cost, and wide detection range. Among them, $\mathrm{SnO}_{2}$-based gas sensors are the most commonly used for the detection of flammable gases. For example, $\mathrm{SnO}_{2}$-based $\mathrm{CH}_{4}$ sensors have attracted considerable attention due to their high sensitivity, high chemical stability, and low cost. However, the ideal working temperature of $\mathrm{SnO}_{2}$-based gas sensors is generally above $300{ }^{\circ} \mathrm{C}$; it will undoubtedly bring high power consumption, which is unexpected in the application of sensors [14]. In the case of $\mathrm{NO}_{2}$ detection, a low working temperature is also required in order to achieve relatively low power consumption and improve the temperature reliability of the sensor. As an ideal gas sensing material, $\mathrm{In}_{2} \mathrm{O}_{3}$ has good development prospects for low temperature gas sensing detection of oxidizing gases, like $\mathrm{NO}_{2}[15,16]$. To improve the $\mathrm{NO}_{2}$ gas sensing performance of $\mathrm{In}_{2} \mathrm{O}_{3}$-based materials, a lot of dopants and catalysts have been exploited and their role in $\mathrm{NO}_{2}$ sensing behavior has been investigated $[17,18]$. Among these dopants and catalysts, $\mathrm{Nb}$ is mainly employed to improve the conductivity and stability of metal oxides [17,19-21], and $\mathrm{Pt}$ is used to enhance the sensing response and selectivity of sensors $[11,18,22]$.

In this paper, a micro hotplate $\mathrm{NO}_{2}$ sensor with an annular heating electrode based on AlN ceramic substrate was designed and fabricated by MEMS technology, in which $\mathrm{Pt} / \mathrm{Nb} / \mathrm{In}_{2} \mathrm{O}_{3}$ composites were used as the sensitive material and $\mathrm{Nb}$-doped $\mathrm{In}_{2} \mathrm{O}_{3}$ with a molar ratio of $\mathrm{In}: \mathrm{Nb}=9: 1$ was prepared by chemical deposition. Finite element thermal simulation analysis of the thermal isolation structure of the sensor was carried out to verify the rationality of the thermal field distribution in the heating region. The thermal response characteristics of the micro hotplate sensor at different power consumptions were studied. The gas sensing properties of the sensor to low concentration and high concentration $\mathrm{NO}_{2}$ were investigated and analyzed in detail. The prepared micro hotplate sensor exhibits good $\mathrm{NO}_{2}$ sensing properties, with a low temperature, low power consumption, and low detection limit.

\section{Thermal Structure Design and Simulation Analysis}

\subsection{Thermal Structure Design of Micro Hotplate Gas Sensor}

The thermal structure design is the key for micro hotplate gas sensors. In order to achieve low power consumption, the "sandwich" structure, in which the metal heater is between the upper and lower insulation layers to reduce power consumption by reducing the area and volume of the heating region, is used in most of traditional silicon-based micro hotplate sensors. However, there are still problems in the thermal stress mismatch and process compatibility between the insulating layer with low thermal conductivity and silicon substrate with high thermal conductivity [23,24]. Fortunately, there are obvious advantages of using AlN over silicon with an insulating layer. As is well known to all, the ratio of the thermal expansion coefficient of $\mathrm{Pt}\left(9.0 \times 10^{-6} / \mathrm{K}\right)$ to $\mathrm{AlN}\left(4.5 \times 10^{-6} /{ }^{\circ} \mathrm{C}\right)$ is smaller (or closer to each other) than that of the silicon substrate $\left(2.5 \times 10^{-6} / \mathrm{K}\right)$ with an insulating layer. In this way, the thermal stress of the $\mathrm{Pt}$ film electrode is smaller and hence the adhesion between the $\mathrm{Pt}$ film and AlN ceramic substrate is better, which is beneficial to improving the quality of the film substrate.

The micro hotplate sensor is designed by a plane structure; that is, the heater electrode and signal electrode are in the same plane, which not only simplifies the process but also solves the problem of thermal stress mismatch and improves the compatibility of sensitive materials.

Figure 1 shows a structural schematic of the ceramic micro hotplate sensor. As shown in Figure 1, the ceramic micro hotplate sensor uses AlN ceramic with good mechanical and thermal properties as the substrate, the Pt film graphic structure on the substrate is the heater electrode and the signal electrode, and the heater electrode adopts the annular structure. The signal electrode is in the center of the heater electrode, which has the outer comb-shaped structure. The comb-shaped signal electrode is 
coated with semiconductor sensitive film, and two semi-annular thermal isolation grooves are etched around the heater electrode. The size of the micro hotplate sensor is $3 \mathrm{~mm} \times 1.8 \mathrm{~mm}$, the width of the thermal isolation groove is $200 \mu \mathrm{m}$, the width of the heater electrode and signal electrode is $50 \mu \mathrm{m}$, and the thickness of the Pt film is about $500 \mathrm{~nm}$.

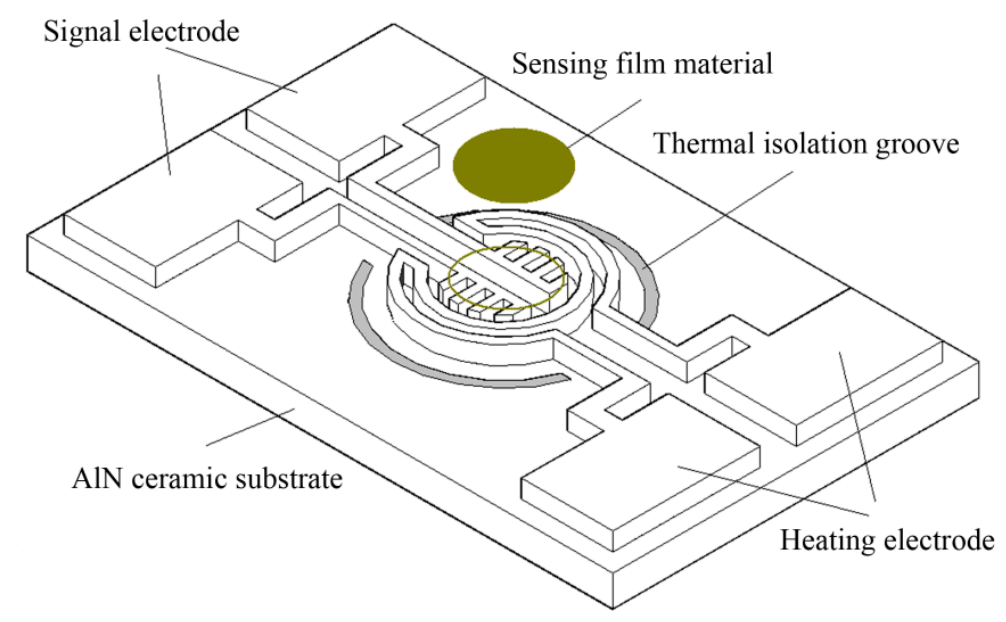

Figure 1. Structural schematic of the ceramic micro hotplate sensor.

The thermal structure design of the micro hotplate sensor is the key factor affecting the thermal distribution of the temperature field. There are two main models for typical thermal field structure distribution, that is, rectangular and circular structure diffusion models. From the theory of thermal diffusion, it can be seen that the circular temperature field is more in line with the analysis of the theoretical model of thermal diffusion [25]. By optimizing the thermal field distribution by thermal structure design, the thermal efficiency and power consumption can be significantly improved, and the temperature gradient effect can be reduced. Figure 2 shows the schematic diagram of thermal diffusion of ceramic micro hotplate sensor structure. It can be observed from Figure 2 that there are three main thermal diffusion pathways in ceramic micro hotplate sensor structures, namely, heat conduction, heat convection, and heat radiation, in which heat loss caused by heat conduction is the main way.

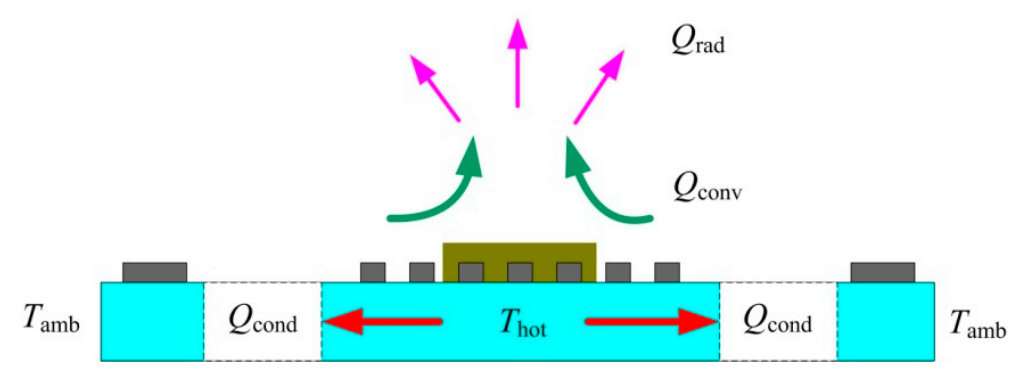

Figure 2. Schematic diagram of the thermal diffusion of ceramic micro hotplate sensor structure.

The heat loss of the micro hotplate sensor is mainly based on the heat conduction of the membrane base, air thermal convection, and thermal radiation [26]. The thermal diffusion equation is as follows:

$$
Q_{\text {tot }}=Q_{\text {cond }}+Q_{\text {conv }}+Q_{\text {rad }}
$$

where $Q_{\text {cond }}$ is the heat conduction loss, $Q_{\text {conv }}$ is the air thermal convection loss, and $Q_{\text {rad }}$ is the thermal radiation loss. Among the three heat dissipation pathways, the thermal isolation structure of micro 
hotplates belongs to a non-closed membrane structure, so the heat conduction of the membrane beam structure is the main heat dissipation way [27]. The equation is as follows:

$$
Q_{\text {cond }}=G_{m} \lambda_{m}\left(T_{\text {hot }}-T_{a m b}\right) \text {, }
$$

where $G_{m}=N A_{\text {beam }} / l$ is the structural geometric factor, which is proportional to the cross-section, $A_{\text {beam }}$, of the membrane beam and inversely proportional to the length, $l$, of the suspended beam. $N$ is the number of membrane beams, $\lambda_{m}$ is the coefficient of heat conduction of the membrane base, and $T_{h o t}$ and $T_{a m b}$ are the heating region temperature and boundary temperature, respectively.

As revealed in Equation (2), $Q_{\text {cond }}$ can be reduced by decreasing the geometric factor, $G_{m}$; the substrate thermal conductivity, $\lambda_{m}$; or the temperature difference, $T_{h o t}-T_{a m b}$. The reduction of $G_{m}$ can be realized by reducing the number of film beams, $N$, reducing the cross-section area, $A_{\text {beam }}$, of membrane beams; or increasing the length, $l$, of film beams. Because the number of film beams, $N$, and the length of film beams, $l$, are limited by scale design, the most effective way is to reduce the thickness of the substrate and the cross-section area of thermal diffusion, $A_{\text {beam }}$. Since the AlN ceramic substrate has high thermal conductivity and difficult to etch, in this paper, the laser etching thermal isolation groove is adopted to form a double-membrane beam suspension bridge structure, which can effectively reduce the diffusion cross-section area, $A_{\text {beam }}$.

The heat loss in air is mainly air heat conduction and temperature difference heat flow exchange loss. The heat conduction coefficient of air at room temperature is $\lambda_{\text {air }}\left(25^{\circ} \mathrm{C}\right)=0.025 \mathrm{~W} \cdot \mathrm{m}^{-1} \cdot{ }^{\circ} \mathrm{C}^{-1}$, and the natural convective heat transfer coefficient of air is $h_{f}=10 \mathrm{~W} \cdot \mathrm{m}^{-2} \cdot \mathrm{K}^{-1}$. In order to simplify the model, assuming that the heat source is a point, according to the spherical coordinate principle, the air heat conduction loss from the radius, $r_{i}$, to $r_{a}$ of the point heat source is shown in Equation (4) [28], and the heat flow exchange loss of air is shown in Equation (5):

$$
\begin{gathered}
Q_{a i r}=Q_{\text {cond }}^{a}+Q_{c o n v}, \\
Q_{\text {cond }}^{a}=\frac{4 \pi \lambda_{\text {air }}\left(T_{h o t}-T_{a m b}\right)}{1 / r_{i}-1 / r_{a}}, \\
Q_{\text {conv }}=A h_{f}\left(T_{\text {hot }}-T_{\text {amb }}\right) .
\end{gathered}
$$

In the thermal steady state, Equations (8) and (9) can be simplified into Equation (6) when boundary dimensions satisfy the condition of $r_{a}>>r_{i}$ :

$$
\begin{aligned}
& Q_{\text {air }}=\left(4 \pi r_{i} \lambda_{\text {air }}+A h_{f}\right)\left(T_{\text {hot }}-T_{\text {amb }}\right) \\
& =\left(G_{\text {air }} \lambda_{\text {air }}+G_{\text {airf }} h_{f}\right)\left(T_{\text {hot }}-T_{\text {amb }}\right),
\end{aligned}
$$

where $\lambda_{\text {air }}$ is the heat conduction coefficient of gas, $h_{f}$ is the convective heat transfer coefficient of gas, $G_{\text {air }}\left(G_{a i r} \approx 4 \pi r_{i}\right)$ and $G_{\text {airf }}\left(G_{\text {airf }} \approx A\right)$ are the structural geometric factors, in which $r_{i}$ is the effective radius of the heating area and $A$ is the effective area of the heating region.

It can be seen from Equation (6) that the heat loss of air, $Q_{a i r}$, is proportional to the temperature difference, $T_{\text {hot }}-T_{a m b}$. In fact, the air heat conduction coefficient, $\lambda_{\text {air }}$, is a variable dependent on the temperature gradient, $\Delta T=T_{h o t}-T_{a m b}$, and the thermal conductivity is related not only to the temperature in the heating region but also to the temperature distribution gradient. With the decrease of the effective radius, $r_{i}$, of the heating region of the micro hotplate, the proportion of the heat flow exchange loss, $Q_{c o n v}$, decreases obviously, and therefore $Q_{c o n d}^{a}$ is the main one in air heat loss, $Q_{a i r}$.

According to the Stefan-Boltzmann law, thermal radiation loss is not only related to the geometric factors of the structure but also to the material and heating temperature, as shown in Equation (7). When the temperature is high, the thermal radiation loss cannot be ignored:

$$
Q_{\text {rad }}=G_{r a d} \sigma \varepsilon\left(T_{h o t}^{4}-T_{a m b}^{4}\right)
$$


where $\varepsilon$ is the radiation coefficient, $\sigma$ is the Boltzmann constant, and the structural geometric factors is $G_{r a d}=A_{s}$ in which $A_{s}$ is the area of the heating region. Normally, when the temperature is not very high $\left(T_{h o t}<200^{\circ} \mathrm{C}\right)$ and the heating area is small $\left(A_{s}<0.5 \mathrm{~mm}^{2}\right)$, the thermal radiation power consumption can usually be ignored below $1 \mathrm{~mW}$.

\subsection{Simulation Analysis of the Thermal Structure of a Micro Hotplate Sensor}

In order to verify the rationality of the thermal structure design of the micro hotplate, the finite element simulation of the thermal structure was carried out by using the ANSYS software. It was assumed that the ideal boundary condition was $25^{\circ} \mathrm{C}$, the chip scale of the sensor was $3 \mathrm{~mm} \times 2 \mathrm{~mm}$, AlN substrate thickness was $0.2 \mathrm{~mm}$, the Pt film thickness was $500 \mathrm{~nm}$, the thermal isolation through hole width was $50 \mu \mathrm{m}$, and the depth was $0.2 \mathrm{~mm}$. The thermal conductivity of AlN and Pt film were $180 \mathrm{~W} \cdot \mathrm{m}^{-1} \cdot{ }^{\circ} \mathrm{C}^{-1}$ and $73 \mathrm{~W} \cdot \mathrm{m}^{-1} \cdot{ }^{\circ} \mathrm{C}^{-1}$, respectively. Under the condition of $1 \times 10^{7} \mathrm{~W} / \mathrm{m}^{3}$ load heat generation rate, Figure 3 shows temperature field distribution maps of the finite element simulation of the thermal structure for the micro hotplate sensor before thermal isolation (a) and (b) after thermal isolation. Here, "STEP" represents the load step; "SUB" represents the load substep;"TIME" indicates the calibration time of the first load step, which is an interval and has no specific time meaning, only when it is related to speed or rate does it mean the real time; "RSYS" is determines the Cartesian coordinate system; SMX and SMN are the abbreviations for Soltion Max and Soltion Min, respectively. Compared with the temperature field distribution of Figure $3 a, b$, it can be observed that the temperature efficiency is obviously improved by the design of the thermal isolation groove, and the maximum temperature (SMX) in the heating region increases from $100.36{ }^{\circ} \mathrm{C}$ before thermal isolation to $239.97^{\circ} \mathrm{C}$ after thermal isolation, and the area of the effective temperature region increases obviously.
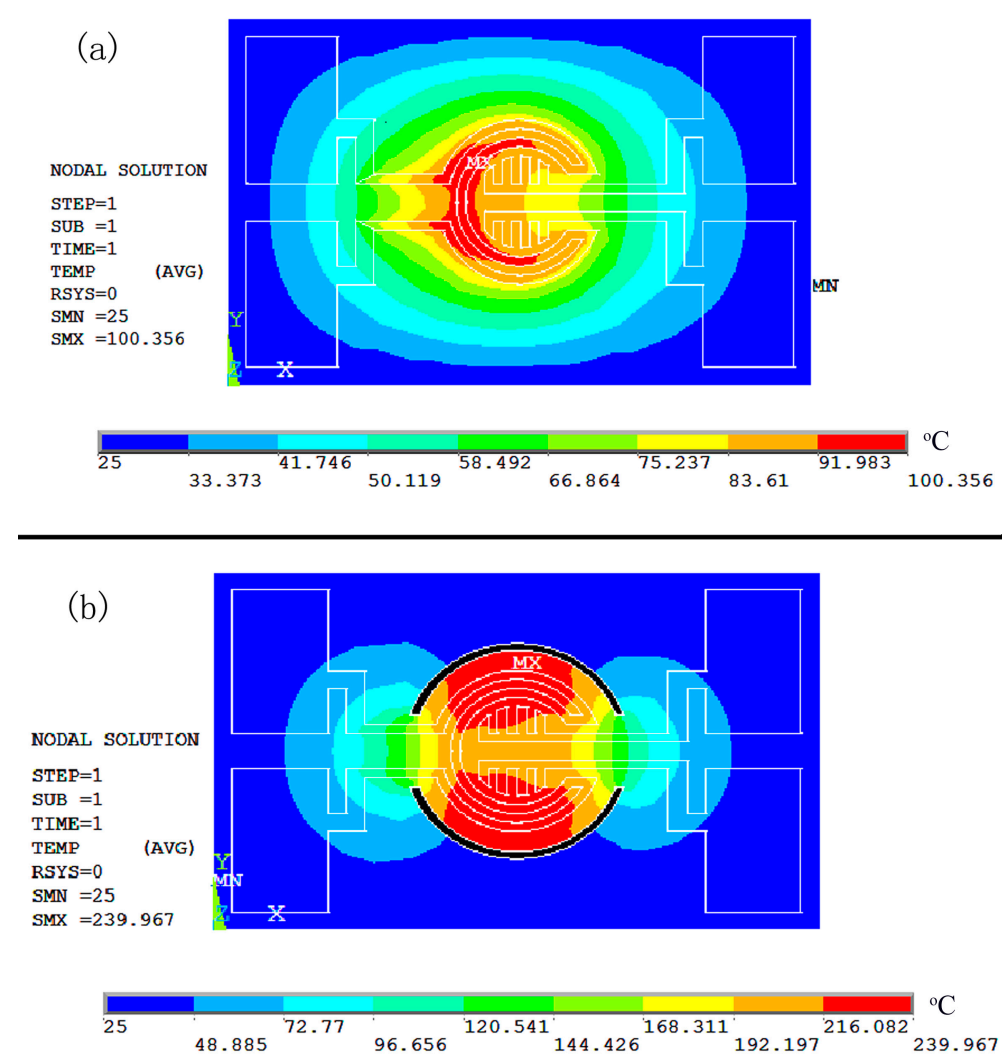

Figure 3. Temperature field distribution maps of finite element simulation of the thermal structure for the micro hotplate sensor (a) before thermal isolation and (b) after thermal isolation. 
Figure 4 is the radial temperature distribution curves before thermal isolation (a) and after thermal isolation (b) of the thermal structure simulation of the micro hotplate sensor, which is used to quantitatively analyze the temperature field distribution and temperature gradient in the center position of the sensor, where the profile is taken with respect to the pictures in Figure 3 top-down for both (a) and (b). As indicated in Figure $4 a, b$, the radial size of the effective equilibrium temperature region of the thermal isolation structure is about $1 \mathrm{~mm}$, and the temperature gradient in the temperature region decreases from $15.10 \%$ before thermal isolation to $6.13 \%$ after thermal isolation. The thermal isolation design obviously reduces the temperature gradient effect, increases the area of the effective temperature region, improves the heat balance efficiency, and plays an important role in improving the temperature characteristics of gas sensing.
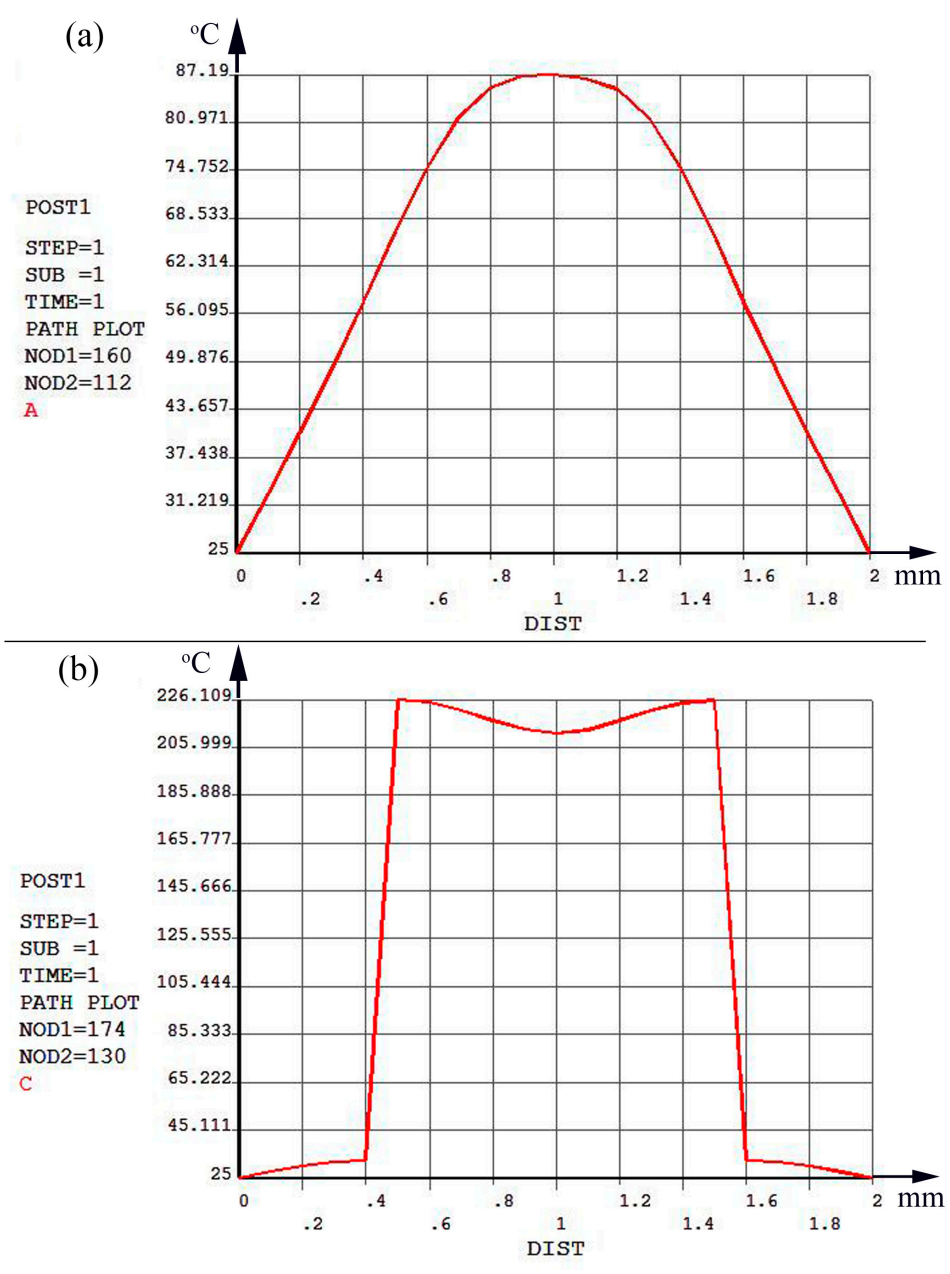

Figure 4. Radial temperature distribution curves (a) before thermal isolation (b) and after thermal isolation of the thermal structure simulation of a micro hotplate sensor.

\section{Experimental}

\subsection{Synthesis and Characterization of Sensitive Materials}

The sensitive material was $\mathrm{Pt} / \mathrm{Nb}_{2} \mathrm{O}_{5} / \mathrm{In}_{2} \mathrm{O}_{3}$, which is abbreviated as "Pt/ $\mathrm{Nb} / \mathrm{In}_{2} \mathrm{O}_{3}$ ". Firstly, $\mathrm{Nb}$-doped $\mathrm{In}_{2} \mathrm{O}_{3}$ oxide powder $\left(\mathrm{Nb} / \mathrm{In}_{2} \mathrm{O}_{3}\right)$ was prepared by chemical deposition. $\operatorname{In}\left(\mathrm{NO}_{3}\right)_{3} \cdot 4.5 \mathrm{H}_{2} \mathrm{O}$ and $\mathrm{Nb}_{2} \mathrm{O}_{5}$ were dissolved in deionized water according to the molar ratio of $\mathrm{In}: \mathrm{Nb}=9: 1$, adding proper amounts of citric acid as a dispersing agent into the mixed solution, and then stirring at $50{ }^{\circ} \mathrm{C}$ for $2 \mathrm{~h}$. Afterwards, ammonia was dripped into the solution to form a milky white precipitate. After separating the precipitate by low-speed centrifugation and washing it for 3 times, the white precipitate was dried at $120^{\circ} \mathrm{C}$ for $2 \mathrm{~h}$, and then was calcined at $500{ }^{\circ} \mathrm{C}$ for $2 \mathrm{~h}$ to obtain yellowish powder. Then, a certain 
amount of $\mathrm{In} / \mathrm{Nb}$ oxide powder was used for agate grinding. A small amount of chloroplatinic acid $\left(\mathrm{H}_{2} \mathrm{PtCl}_{6}\right)$ and terpineol were dripped into the $\mathrm{Nb} / \mathrm{In}_{2} \mathrm{O}_{3}$ oxide powder to form the slurry. After that, the sensitive material slurry was coated onto the $0.25-\mathrm{mm}$ radius circular area of the comb-shaped signal electrode outside the sensor. Finally, the $\mathrm{Pt} / \mathrm{Nb} / \mathrm{In}_{2} \mathrm{O}_{3}$ composite semiconductor oxide sensitive material was formed by sintering semiconductor slurry film at $500{ }^{\circ} \mathrm{C}$ for $2 \mathrm{~h}$ in a furnace. All chemicals used in the synthesis were analytic grade reagents without further purification.

Figure 5 is the SEM image of the $\mathrm{Nb} / \mathrm{In}_{2} \mathrm{O}_{3}$ oxide sensing film. It was found that the composite oxide nanoparticles are regular, the agglomeration is less, and the interface of the particles is clear, which is very beneficial to the contact between the gas and the surface of nanoparticles.

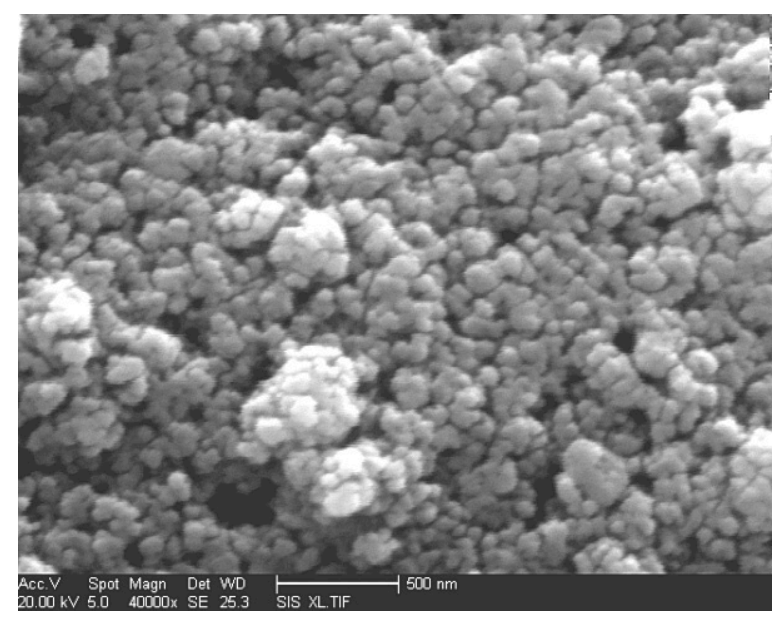

Figure 5. SEM images of the $\mathrm{Nb} / \mathrm{In}_{2} \mathrm{O}_{3}$ sensing film.

\subsection{Fabrication of the Gas Sensor}

An AlN-based ceramic micro hotplate gas sensor chip was prepared by a flexible mechanical lithography peeling process and precision laser micro-machining etching. The electrode pattern of the Pt film sensor was formed on a $0.2-\mathrm{mm}$ thick AlN ceramic substrate by a flexible mechanical lithography peeling process, in which the thickness of the $\mathrm{Pt}$ film was about $500 \mathrm{~nm}$. The thermal isolation groove around the heater was prepared by laser etching. The width of the thermal isolation groove was about $50 \mu \mathrm{m}$, and its depth was $0.2 \mathrm{~mm}$, which is the same as the thickness of the AlN substrate.

Figure 6 is the real photograph of the sensor's sealing structure. Both the heating electrode and the signal electrode used $\mathrm{Pt}$ film with good temperature characteristics and were distributed in the same plane. The comb-shaped signal electrode formed a circular sensitive area with a radius of $0.25 \mathrm{~mm}$ in the center of the annular heating electrode, and the composite semiconductor sensitive material $\mathrm{Pt} / \mathrm{Nb}_{2} \mathrm{O}_{5} / \mathrm{In}_{2} \mathrm{O}_{3}$ was coated on the sensitive area in a thick film form. In order to reduce the contact thermal conductivity loss of the micro hotplate, the sensor chip adopted a suspension sealing structure, in which platinum wire with a diameter of $0.08 \mathrm{~mm}$ was used as the welding lead, and platinum slurry was used for sintering welding at $850{ }^{\circ} \mathrm{C}$. In order to improve the welding quality of the chip and platinum wire, the chip pad was fixed by drilling and piercing, which significantly improved the welding reliability. Platinum wire lead welding adopted $850{ }^{\circ} \mathrm{C}$ platinum slurry sintering welding. This step was completed before the sensor sensitive material film formed, that is, the $500{ }^{\circ} \mathrm{C}$ sensitive material film sintering step began after $850{ }^{\circ} \mathrm{C}$ platinum slurry sintering welding. Consequently, the thickness of the sensitive material film (top gray-white region) after coating on the signal electrode was about $15 \mu \mathrm{m}$ as shown in Figure S1 (see Supplementary Materials). 


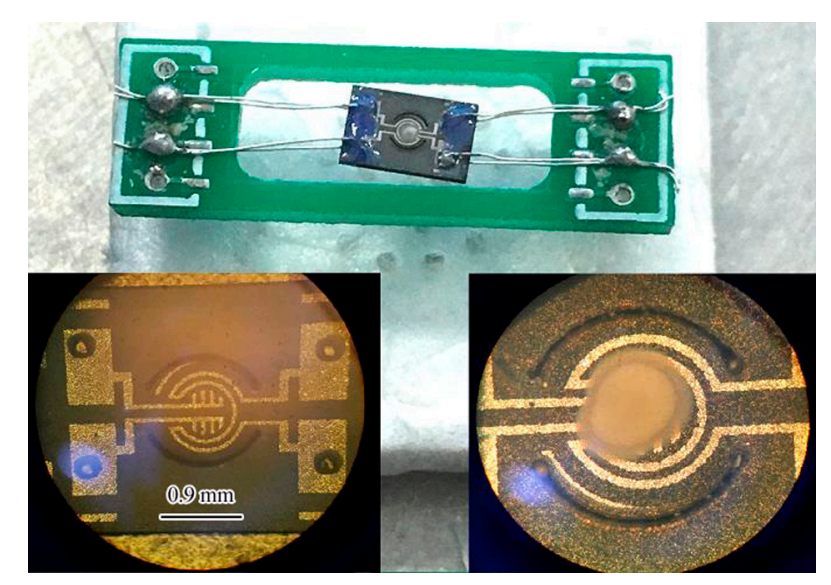

Figure 6. The real photograph of the sensor sealing structure.

\section{Results and Discussion}

\subsection{Measurement of Thermal Response Characteristics}

The length of the heating stability time of micro hotplate sensor is an important parameter to realize rapid detection. It is only when the thermal response reaches the thermal balance stability that the static gas sensing detection can be carried out, so the thermal response equilibrium rate is also an important factor affecting the gas sensitivity response rate. In addition, the thermal gradient effect is related to the thermal response rate. The thermal response rate of the substrate with high thermal conductivity is fast and the thermal gradient effect is small, but the heat conduction loss is large, and the substrate material with low thermal conductivity is just the opposite. In order to increase the thermal response rate and reduce the influence of the thermal gradient effect, the thermal isolation groove is designed around the heating region of the sensor substrate. In this way, the reduction can be realized in the heat conduction loss and decrease the thermal diffusion path at the same time, which will reduce the thermal gradient and increase the heat balance rate. In addition, to measure the temperature characteristics of the sensor, we designed a temperature sensor with the same structure as the prepared sensor, as shown in Figure S2 (see Supplementary Materials).

Figure 7 shows the thermal response characteristic curves of the sensor at different power consumptions before thermal isolation (a) and after thermal isolation (b). It can be seen that the larger the power consumption is, the longer the thermal response time will be, but after the thermal isolation design, the average thermal response time decreases from about $8 \mathrm{~s}$ before isolation to about $3 \mathrm{~s}$ after isolation, and the thermal response rate is obviously increased, and the thermal field temperature is also increased under the same heating power consumption, which indicates that the thermal isolation design has an important influence on increasing the thermal response rate and reducing the power consumption, and plays an obvious role in improving the thermal response characteristics.

As is well known to all, the response time of gas sensing is determined by the electron exchange rate between gas molecules and the surface of sensitive materials, which is affected by many factors, such as gas species, gas concentration, sensitive material properties, temperature, etc. Among them, the temperature level and temperature gradient of the sensor are the important factors that affect the gas sensing response rate, which determines the thermal stability time of the sensor heater and affects the gas sensing response time. As shown in Figure 7, the thermal response time of the sensor decreases from 8 to $3 \mathrm{~s}$ before and after thermal isolation, and the thermal response time of the sensor increased by $5 \mathrm{~s}$, and hence the thermal performance of the sensor is obviously improved. However, the response time of the high concentration $\mathrm{NO}_{2}$ gas sensor is only about $40 \mathrm{~s}$ at $150 \mathrm{~mW}$. Therefore, it still has great influence on the response time of high concentration $\mathrm{NO}_{2}$ gas sensors. 

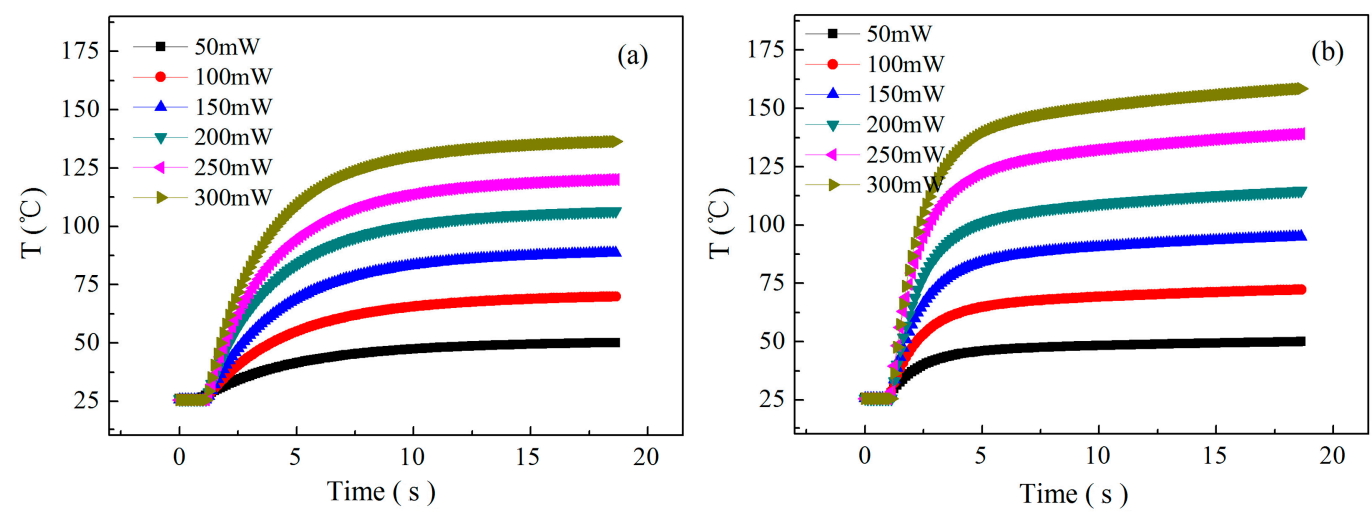

Figure 7. The thermal response characteristic curves of the sensor at different power consumptions (a) before thermal isolation and (b) after thermal isolation.

In addition, the temperature difference before and after thermal isolation shown in Figure 7 is indeed obviously smaller than the temperature difference in Figure 3. We believe that the reason may be discussed as follows: (1) The ideal parameters are set in Figure 3 of the simulation section and the simulation results do not take into account the actual boundary conditions and environmental effects; and (2) the actual measurement process needs encapsulation and connection, which will reduce the temperature effect. Although the design does not achieve the desired effect, it can be clearly seen from Figure 7 that thermal isolation can not only improve the thermal response rate but also improve the temperature effect, and play a significant role in reducing power consumption.

There are two ways to reduce the power consumption of micro hotplate gas sensors. One is to develop low-temperature sensitive materials, the other is to miniaturize the structure size and optimize the structure design. In this paper, it is important to improve the efficiency of electrothermal coupling and accelerate the electron exchange rate of gas sensitive adsorption by optimizing the structure design to reduce the temperature gradient effect. Figure 8 shows the relationship between the power consumption and temperature characteristics of the micro hotplate sensor. Under the heating power consumption of $150 \mathrm{~mW}$, the operating temperature of the sensor is only about $94{ }^{\circ} \mathrm{C}$, and the operating temperature of the sensor is in the range of 90 to $200{ }^{\circ} \mathrm{C}$ at a power consumption range of 150 to $500 \mathrm{~mW}$. There is an approximate linear relationship between power consumption and temperature.

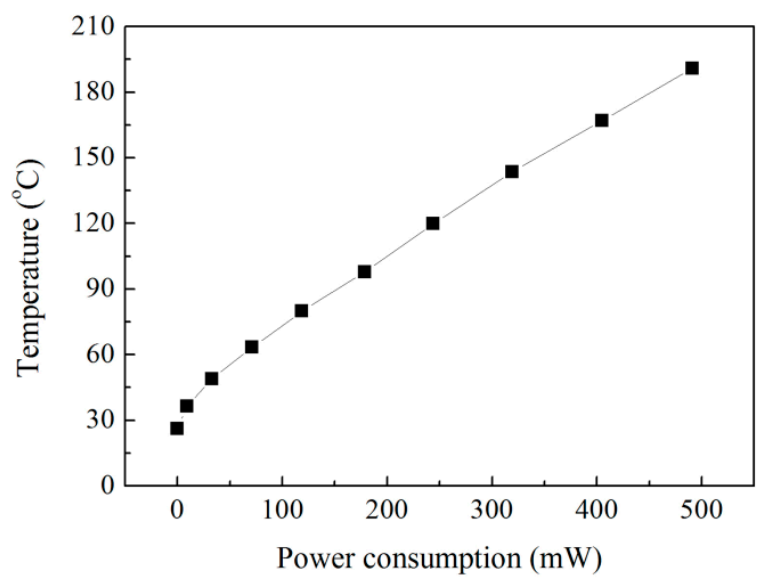

Figure 8. The relationship between the power consumption and temperature characteristics of the micro hotplate sensor.

\subsection{Gas Sensing Response Characteristics of Low Concentration $\mathrm{NO}_{2}$}

In static testing mode, the $\mathrm{NO}_{2}$ sensitivity response tests were carried out over a low concentration range of 1 to $10 \mathrm{ppm}$ at different heating power consumption of 100,150, and $200 \mathrm{~mW}$, as shown in 
Figure 9a-c. It is found that the gas sensing response characteristics of low concentration $\mathrm{NO}_{2}$ at different heating power consumptions are obviously different, in which the recovery rate of the gas sensing response is relatively slow under the heating power consumption of $100 \mathrm{~mW}$, so it is difficult to achieve the response balance, which indicates that the heating temperature of the micro hotplate sensor does not reach the ideal working conditions. However, the good gas sensing characteristics of low concentration $\mathrm{NO}_{2}$ are obtained at the power consumption of 150 and $200 \mathrm{~mW}$. In this condition, the effective equilibrium can be achieved, and the response recovery rate is ideal. By comparing the 2 ppm $\mathrm{NO}_{2}$ sensing response curves of different power consumptions shown in Figure $9 \mathrm{~d}$, it is obvious that the response $\left(R_{\mathrm{g}} / R_{\mathrm{a}}\right)$ of $2 \mathrm{ppm} \mathrm{NO} \mathrm{N}_{2}$ at $150 \mathrm{~mW}$ is the best, and the response and recovery time are about 180 and $300 \mathrm{~s}$, respectively, so it has ideal comprehensive gas sensing characteristics.
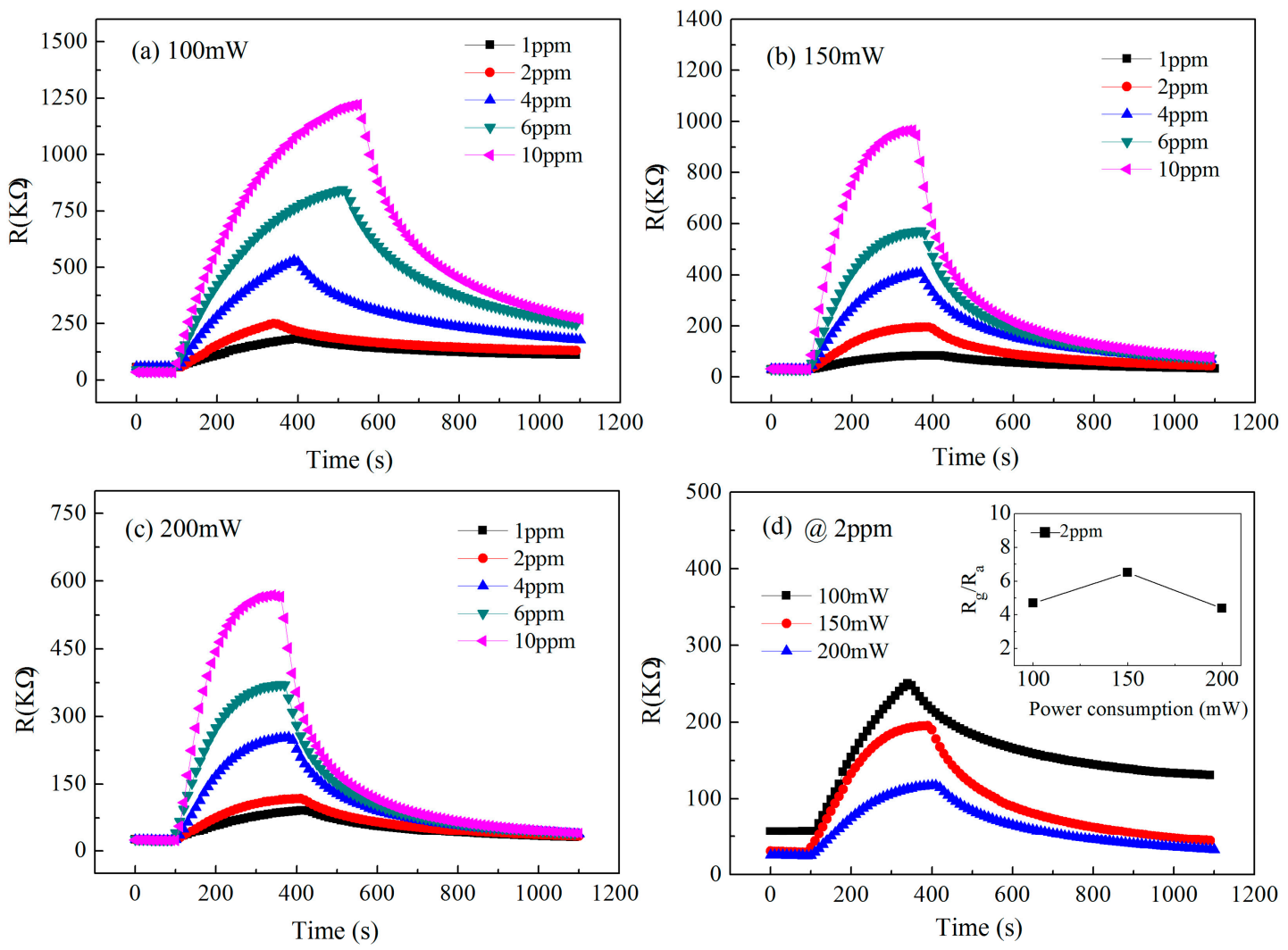

Figure 9. Gas sensing response characteristic curves of the micro hotplate sensor detecting low concentration $\mathrm{NO}_{2}$ at different power consumptions of (a) 100, (b) 150, and (c) $200 \mathrm{~mW}$, and (d) at a fixed concentration of $2 \mathrm{ppm}$.

Compared with Figure $9 \mathrm{a}-\mathrm{c}$, the gas sensing response characteristics of 1 to $10 \mathrm{ppm}$ low concentration $\mathrm{NO}_{2}$ at different heating power consumptions are obviously different, in which the recovery rate of the gas sensing response is slow at $100 \mathrm{~mW}$, and it is difficult to achieve the response balance, indicating that the heating temperature of the micro hotplate sensor below $100 \mathrm{~mW}$ does not reach ideal working conditions. However, it is easier to achieve good gas sensing characteristics for the micro hotplate sensor at 150 and $200 \mathrm{~mW}$, the effective equilibrium state can be achieved, and the response recovery rate is ideal. As shown in the inset from Figure $9 \mathrm{~d}$, it can be seen that the response $\left(R_{\mathrm{g}} / R_{\mathrm{a}}\right)$ at $150 \mathrm{~mW}$ to $2 \mathrm{ppm} \mathrm{NO} \mathrm{Ni}_{2}$ is the highest. Taking the time needed to reach $90 \%$ of the stable value and restoring the stable value of the gas sensing response as the response and recovery time, $T_{90}$ and $t_{90}$ are used to represent the response and recovery time, respectively. The response and recovery time of the micro hotplate sensor to $2 \mathrm{ppm} \mathrm{NO}_{2}$ at $150 \mathrm{~mW}$ are about $T_{90}=180 \mathrm{~s}$ and $t_{90}=10 \mathrm{~min}$, respectively. 


\subsection{Gas Sensing Response Characteristics of High Concentration $\mathrm{NO}_{2}$}

Wide-range detection is one of the advantages of semiconductor micro hotplate gas sensors over other types of sensors. The above results of the gas sensing response of low concentration $\mathrm{NO}_{2}$ allow us to confirm the optimal power consumption of $150 \mathrm{~mW}$. To further confirm that the good gas sensing characteristics can be achieved in a wider concentration range for $\mathrm{In} / \mathrm{Nb} / \mathrm{Pt}$ thick-film micro hotplate sensors, the $\mathrm{NO}_{2}$ sensing response and recovery property curves of the sensor were also carried out in the concentration range of 5 to $100 \mathrm{ppm}$ at different heating power consumptions of 150, 200, 250, and $300 \mathrm{~mW}$ as shown in Figure 10. With the increase of the heating power consumption, the working temperature will increase accordingly, the resistance of the sensor in air decreases obviously, and the gas sensitivity response rate increases obviously with the increase of the gas concentration measured. In order to further illustrate the effect of power consumption on the gas sensing response time, Figure 11 shows the gas sensing response characteristic curves at different heating power consumptions to $100 \mathrm{ppm} \mathrm{NO} \mathrm{N}_{2}$, in which the response time, $T_{90}$, is about $40 \mathrm{~s}$ at $150 \mathrm{~mW}$ and the recovery rate, $t_{90}$, is about $60 \mathrm{~s}$, and the response time is significantly slower with the increase of the heating power consumption.
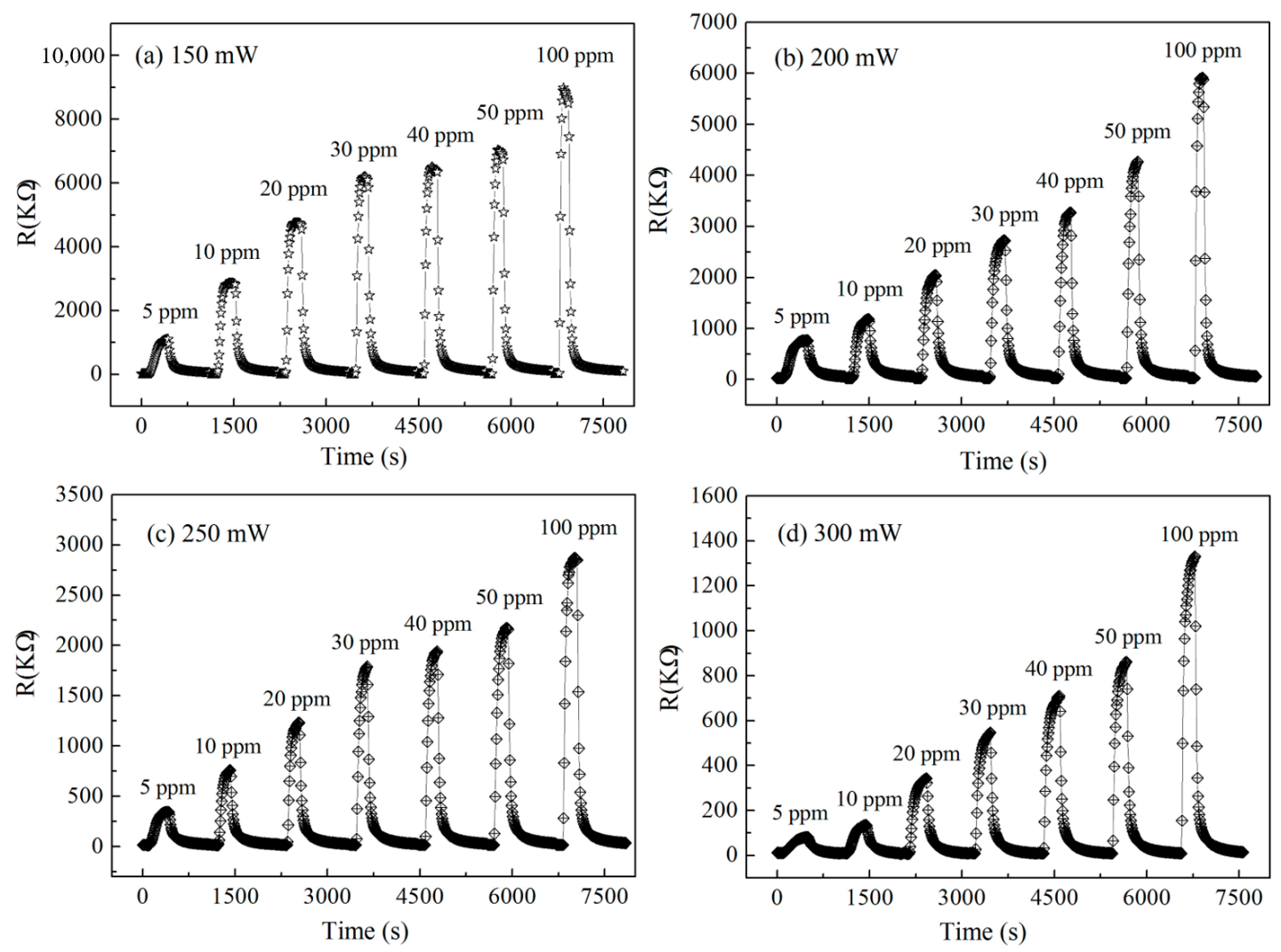

Figure 10. Gas sensing response and recovery property curves of the micro hotplate sensor detecting high concentration $\mathrm{NO}_{2}$ at different power consumptions of (a) 150; (b) 200; (c) 250; and (d) $300 \mathrm{~mW}$ in the range of 5 to $100 \mathrm{ppm}$.

As indicated in Figure 11, with the increase of the heating power consumption, the response of the sensor to $100 \mathrm{ppm} \mathrm{NO}$ shows a downward trend, in which the sensitivity curve of 200 and $250 \mathrm{~mW}$ is intersecting, and the sensitivity is higher at $150 \mathrm{~mW}$, which is consistent with the response change of $2 \mathrm{ppm} \mathrm{NO}_{2}$ in Figure 9d, indicating that the sensor has higher sensitivity at $150 \mathrm{~mW}$.

In order to further analyze the influence of different heating power consumptions on the gas sensitivity response characteristics, Figure 12 shows the sensitivity curve of the sensor of different heating power consumptions. As can be seen from Figure 12, with the increasing power consumption, the sensitivity of $\mathrm{NO}_{2}$ shows a downward trend, and the sensitivity is the highest at $150 \mathrm{~mW}$, which 
indicates that the sensor has higher sensitivity and a faster response rate at $150 \mathrm{~mW}$ compared with other power consumptions.

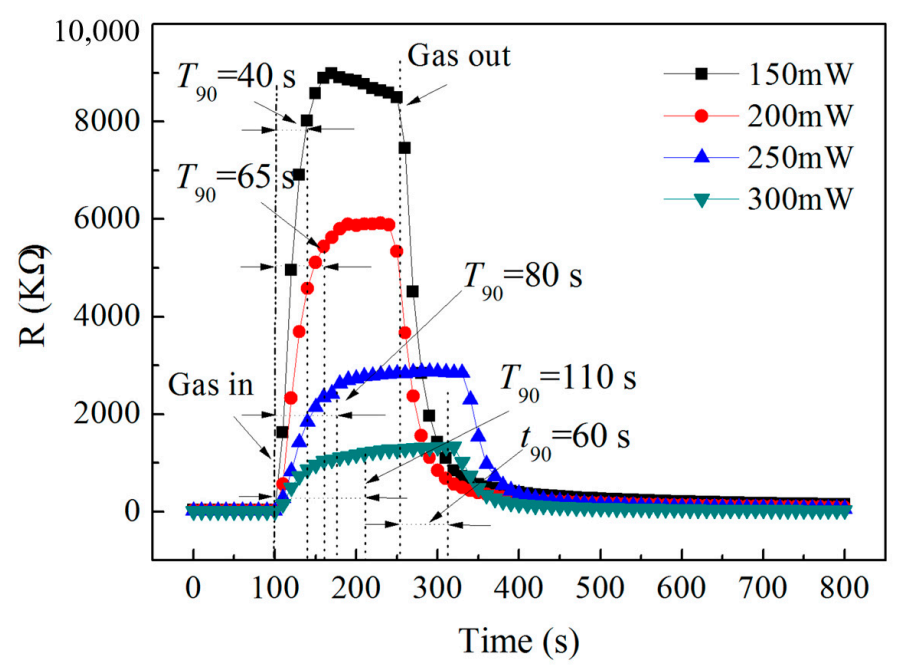

Figure 11. The gas sensing response characteristic curves at different heating power consumptions to 100 ppm $\mathrm{NO}_{2}$.

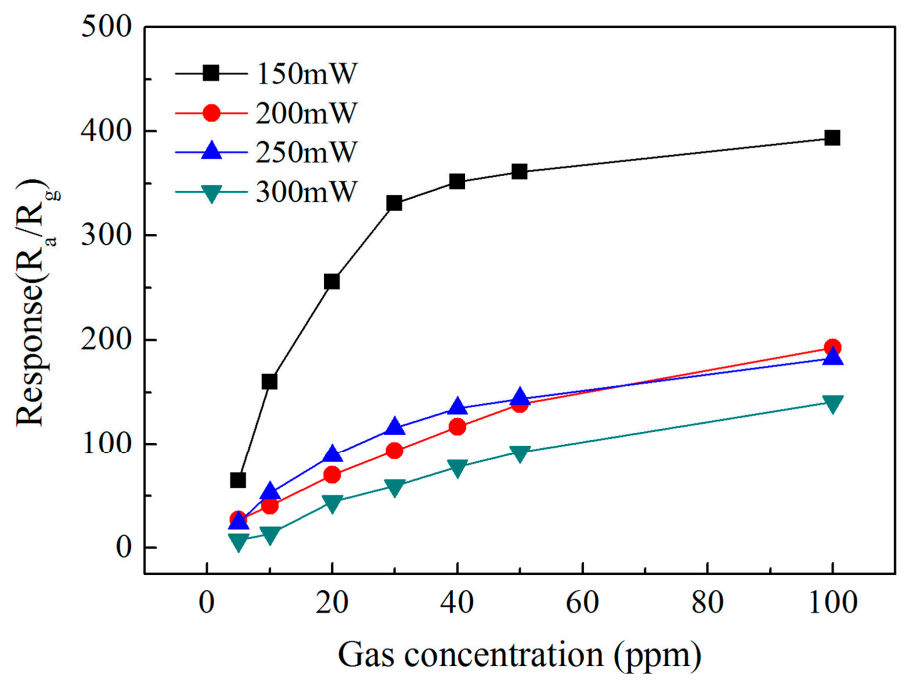

Figure 12. Variation of the response to $\mathrm{NO}_{2}$ with the gas concentration at different power consumptions.

Taking the abovementioned results into consideration, the attained $\mathrm{Pt} / \mathrm{Nb} / \mathrm{In}_{2} \mathrm{O}_{3}$ sensor has a low operating temperature of $94{ }^{\circ} \mathrm{C}$ and rapid response time of $180 \mathrm{~s}$ to $1 \mathrm{ppm} \mathrm{NO}_{2}$ at $150 \mathrm{mw}$ power consumption, which is superior to several other gas sensors reported as $\operatorname{In}_{2} \mathrm{O}_{3}$-based sensors as listed in Table 1. Although it is slightly inferior compared with Fe- $\operatorname{In}_{2} \mathrm{O}_{3}$ and $\mathrm{Pt}-\mathrm{In}_{2} \mathrm{O}_{3} \mathrm{MCs}$ sensors, which exhibit a high response of 71 and 44.9 at a low $\mathrm{NO}_{2}$ concentration of $1 \mathrm{ppm}$, the response $(2.87$ to $1 \mathrm{ppm}$ $\mathrm{NO}_{2}$ ) of the $\mathrm{Pt} / \mathrm{Nb} / \mathrm{In}_{2} \mathrm{O}_{3}$ sensor in our work is comparable to that of $\operatorname{In}_{2} \mathrm{O}_{3}$ nanowires (2.57 to $1 \mathrm{ppm}$ $\mathrm{NO}_{2}$ ). Our findings provide a potential application for $\operatorname{In}_{2} \mathrm{O}_{3}$-based gas sensors in highly effective and low concentration $\mathrm{NO}_{2}$ detection. 
Table 1. Comparison of the sensing performance of various $\mathrm{NO}_{2}$ gas sensors based on $\mathrm{In}_{2} \mathrm{O}_{3}$.

\begin{tabular}{ccccccc}
\hline Materials & $\begin{array}{c}\text { Operation } \\
\text { Temperature }\left({ }^{\circ} \mathbf{C}\right)\end{array}$ & $\begin{array}{c}\text { Concentration } \\
(\mathbf{p p m})\end{array}$ & $\begin{array}{c}\text { Response } \\
\left(\boldsymbol{R}_{\mathbf{g}} / \boldsymbol{R}_{\mathbf{a}}\right)\end{array}$ & $\begin{array}{c}\text { Response } \\
\text { Time }(\mathbf{s})\end{array}$ & $\begin{array}{c}\text { Recovery } \\
\text { Time (min) }\end{array}$ & Reference \\
\hline $\mathrm{In}_{2} \mathrm{O}_{3}$ nanowires & 250 & 1 & 2.57 & $\mathrm{~N} / \mathrm{A}$ & $\mathrm{N} / \mathrm{A}$ & {$[29]$} \\
$\mathrm{Pt}-\mathrm{In}_{2} \mathrm{O}_{3}$ & 250 & 5 & 1904 & 330 & 14 & {$[30]$} \\
$\mathrm{Fe}-\mathrm{In}_{2} \mathrm{O}_{3}$ & 150 & 1 & 71 & 276 & 2.5 & {$[31]$} \\
$\mathrm{Pt} / \mathrm{In} \mathrm{O}_{3} \mathrm{MCs}$ & 40 & 1 & 44.9 & $\mathrm{~N} / \mathrm{A}$ & 7 & {$[12]$} \\
$\mathrm{Pt} / \mathrm{Nb} / \mathrm{In}_{2} \mathrm{O}_{3}$ & 94 & 1 & 2.87 & 180 & 10 & This work \\
\hline
\end{tabular}

\section{Conclusions}

In summary, a planar structural micro hotplate $\mathrm{NO}_{2}$ gas sensor based on $\mathrm{AlN}$ ceramic substrate with an annular heater was designed and prepared by MEMS technology, in which $\mathrm{Pt} / \mathrm{Nb} / \mathrm{In}_{2} \mathrm{O}_{3}$ composites were used as the sensitive material. Finite element simulation analysis of the thermal isolation structure of the sensor was carried out by using ANSYS software, which verified the rationality of the thermal isolation structure design and the feasibility of the preparation process. The thermal response characteristic tests of different power consumptions were investigated and analyzed, and the gas sensing response performance of the micro hotplate gas sensor was studied and discussed in detail over a low concentration range of 1 to $10 \mathrm{ppm}$ and a high concentration range of 5 to $100 \mathrm{ppm}$ under different heating power consumption conditions. The results demonstrate that the optimal operating temperature is $94{ }^{\circ} \mathrm{C}$ and the optimal heating power consumption is $150 \mathrm{~mW}$. The low temperature, low power consumption, and low concentration detection of the prepared $\mathrm{NO}_{2}$ gas sensor provide a potential way for detecting air pollution.

Supplementary Materials: The following are available online at http://www.mdpi.com/1424-8220/19/17/3719/s1, Figure S1: SEM sectional image of sensitive materials, Figure S2: The structure of temperature sensor.

Author Contributions: W.-J.Z. methodology, data curation, original draft preparation; D.X. formal analysis, investigation, review and editing; Y.-S.C. software, resources; X.W. and Y.-B.S. supervision.

Funding: This research was funded by the National Natural Science Youth Foundation of China (61803128, 61501149), Postdoctoral Fund of China (2016M601437), and Natural Science Foundation of Heilongjiang Province (LH2019F026).

Conflicts of Interest: The authors declare no conflict of interest.

\section{References}

1. Zhang, C.; Luo, Y.; Xu, J.; Debliquy, M. Room Temperature Conductive Type Metal Oxide Semiconductor Gas Sensors for $\mathrm{NO}_{2}$ Detection. Sens. Actuators A Phys. 2019, 289, 118-133. [CrossRef]

2. Mothe, G.; Castro, M.; Sthel, M.; Lima, G.; Brasil, L.; Campos, L.; Rocha, A.; Vargas, H. Detection of Greenhouse Gas Precursors from Diesel Engines Using Electrochemical and Photoacoustic Sensors. Sensors 2010, 10, 9726-9741. [CrossRef] [PubMed]

3. Mengis, T.; Genty, F.; Aubert, T. Analysis of $\mathrm{NO}_{2}$ Absorption Cross-sections at High Temperature for the Development of Postcombustion Gases Optical Sensor. In Proceedings of the 2015 IEEE Workshop on Environmental, Energy and Structural Monitoring Systems (EESMS), Trento, Italy, 9-10 July 2015; pp. 141-145.

4. Lin, C.; Gillespie, J.; Schuder, M.D.; Beverland, I.J.; Heal, M.R. Evaluation and Calibration of Aeroqual Series 500 Portable Gas Sensors for Accurate Measurement of Ambient Ozone and Nitrogen Dioxide. Atmos. Environ. 2015, 100, 111-116. [CrossRef]

5. Zhang, F.; Shi, L.; Zhao, J.; Zheng, Y.; Xiao, Y.; Zheng, Y.; Jiang, L. Pyrochlore $\operatorname{Pr}_{2} Z_{2-x} \mathrm{M}_{x} \mathrm{O}_{7}(\mathrm{M}=\mathrm{Al}, \mathrm{Ga}, \mathrm{In})$ Solid-state Electrolytes: Defect-mediated Oxygen Hopping Pathways and Enhanced $\mathrm{NO}_{2}$ Sensing Properties. Sens. Actuators B Chem. 2018, 270, 130-139. [CrossRef]

6. Qi, W.; Li, W.; Sun, Y.; Guo, J.; Xie, D.; Cai, L.; Zhu, H.; Xiang, L.; Ren, T. Influence of Low-dimension Carbon-based Electrodes on the Performance of $\mathrm{SnO}_{2}$ Nanofiber Gas Sensors at Room Temperature. Nanotechnology 2019, 30, 345503. [CrossRef] [PubMed]

7. Wang, Y.; Fan, S.-H.; Wang, S.-L. Chemiluminescence Determination of Nitrogen Oxide in Air with a Sequential Injection Method. Anal. Chim. ACTA 2005, 541, 131-136. [CrossRef] 
8. Lsiugo, K.; Newman, N.; Jandarov, R.; Grinshpun, S.A.; Reponen, T. Assessing the Accuracy of Commercially Available Gas Sensor for the Measurement of Ambient Ozone and Nitrogen dioxide. J. Occupa. Environ. Hyg. 2018, 15, 782-791.

9. Malings, C.; Tanzer, R.; Hauryliuk, A.; Kumar, S.P.N.; Zimmerman, N.; Kara, L.B.; Presto, A.A.; Subramanian, R. Development of a General Calibration Model and Long-term Performance Evaluation of Low-cost Sensors for Air Pollutant Gas Monitoring. Atmos. Measure. Tech. 2019, 12, 903-920. [CrossRef]

10. Zimmerman, N.; Presto, A.A.; Kumar, S.P.; Gu, J.; Hauryliuk, A.; Robinson, E.S.; Robinson, A.L.; Subramanian, R. A machine Learning Calibration Model Using Random Forests to Improve Sensor Performance for Lower-cost Air Quality Monitoring. Atmos. Measure. Tech. 2018, 11, 291-313. [CrossRef]

11. Wang, Y.; Liu, C.; Wang, Z.; Song, Z.; Zhou, X.; Han, N.; Chen, Y. Sputtered $\mathrm{SnO}_{2}$ : NiO Thin Films on Self-Assembled Au Nanoparticle Arrays for MEMS Compatible $\mathrm{NO}_{2}$ Gas Sensors. Sens. Actuators B Chem. 2019, 278, 28-38. [CrossRef]

12. Liu, Y.; Liu, X.; Wang, Y.; Zhang, T. Metal-organic-framework-derived $\operatorname{In}_{2} \mathrm{O}_{3}$ Microcolumnar Sructures Embedded with Pt Nanoparticles for $\mathrm{NO}_{2}$ Detection Near Room Temperature. Ceram. Intern. 2019, 45, 9820-9828. [CrossRef]

13. Akamatsu, T.; Itoh, T.; Izu, N.; Shin, W. $\mathrm{NO}$ and $\mathrm{NO}_{2}$ Sensing Properties of $\mathrm{WO}_{3}$ and $\mathrm{Co}_{3} \mathrm{O}_{4}$ Based Gas Sensors. Sensors 2013, 13, 12467-12481. [CrossRef] [PubMed]

14. Xu, K.; Tian, S.; Zhu, J.; Yang, Y.; Shi, J.; Yu, T.; Yuan, C. High Selectivity of Sulfur-Doped $\mathrm{SnO}_{2}$ in $\mathrm{NO}_{2}$ Detection at Lower Operating Temperatures. Nanoscale 2018, 10, 20761-20771. [CrossRef] [PubMed]

15. Ma, H.; Yu, L.; Yuan, X.; Li, Y.; Li, C.; Yin, M.; Fan, X. Room Temperature Photoelectric $\mathrm{NO}_{2}$ Gas Sensor Based on Direct Growth of Walnut-like $\mathrm{In}_{2} \mathrm{O}_{3}$ Nanostructures. J. Alloy. Comp. 2018, 782, 1121-1126. [CrossRef]

16. You, R.; Han, D.-D.; Liu, F.M.; Zhang, Y.-L.; Lu, G.Y. Fabrication of Flexible Room-temperature $\mathrm{NO}_{2}$ Sensors by Direct Laser Writing of $\operatorname{In}_{2} \mathrm{O}_{3}$ and Grapheme Oxide Composites. Sens. Actuators B Chem. 2018, 277, 114-120. [CrossRef]

17. Hu, Y.; Hu, X.; Qiu, J.; Quan, W.; Qin, W.; Min, X.; Lu, S.; Chen, S.; Du, W.; Chen, X. Nitric Oxide Detector Based on $\mathrm{WO}_{3}-1 w \mathrm{t} \% \mathrm{In}_{2} \mathrm{O}_{3}-1 \mathrm{wt} \% \mathrm{Nb}_{2} \mathrm{O}_{5}$ with State-of-the-Art Selectivity and ppb-Level Sensitivity. ACS Appl. Mater. Inter. 2018, 10, 42583-42592. [CrossRef] [PubMed]

18. Xu, X.; Fan, H.; Liu, Y.; Wang, L.; Zhang, T. Au-loaded $\mathrm{In}_{2} \mathrm{O}_{3}$ Nanofibers-based Ethanol Micro Gas Sensor with Low Power Consumption. Sens. Actuators B Chem. 2011, 160, 713-719. [CrossRef]

19. Zeng, W.; Liu, T.; Wang, Z. Impact of $\mathrm{Nb}$ Doping on Gas-sensing Performance of $\mathrm{TiO}_{2}$ Thick-film Sensors. Sens. Actuators B Chem. 2012, 166, 141-149. [CrossRef]

20. Comini, E.; Ferroni, M.; Guidi, V.; Vomiero, A.; Merli, P.G.; Morandi, V.; Sacerdoti, M.; Mea, G.D.; Sberveglieri, G. Effects of $\mathrm{Ta} / \mathrm{Nb}$-doping on titania-based thin films for gas-sensing. Sens. Actuators B Chem. 2005, 108, 21-28. [CrossRef]

21. Kruefu, V.; Liewhiran, C.; Wisitsoraat, A.; Phanichphant, S. Selectivity of Flame-spray-made Nb/ZnO Thick Films towards $\mathrm{NO}_{2}$ Gas. Sens. Actuators B Chem. 2011, 156, 360-367. [CrossRef]

22. He, X.; Li, J.; Gao, X. Effect of $\mathrm{V}_{2} \mathrm{O}_{5}$ Coating on $\mathrm{NO}_{2}$ Sensing Properties of $\mathrm{WO}_{3}$ Thin Films. Sens. Actuators $B$ Chem. 2005, 108, 207-210. [CrossRef]

23. Jang, B.; Kim, W.; Song, M.-J.; Lee, W. Thermal Stability of the Sensing Properties in $\mathrm{H}_{2}$ Sensors Composed of Pd Nanogaps on an Elastomeric Substrate. Sens. Actuators B Chem. 2017, 240, 186-192. [CrossRef]

24. Wiche, G.; Berns, A.; Steffes, H.; Obermeler, E. Thermal Analysis of Silicon Carbide Based Micro Hotplates for Metal Oxide Gas Sensors. Sens. Actuators A Phys. 2005, 123, 12-17. [CrossRef]

25. Zhao, W.; Wang, X.; Wang, X. Thermal Interference Analysis of Ceramic Micro-plate Thermal-isolated Gas Sensor Arrays. Chin. J. Sci. Ins. 2016, 37, 579-585.

26. Yu, J.; Tang, Z.; Huang, Z. Thermal Crosstalk of Micro Hotplate Arrays. J. Semi. 2008, 29, 1581-1584.

27. Simon, I.; Barsan, N.; Bauer, M. Micro-machined Metal Oxide Gas Sensors: Opportunities to Improve Sensor Performance. Sens. Actuators B Chem. 2001, 73, 1-26. [CrossRef]

28. Lalinsky, T.; Drzik, M.; Jakovenko, J.; Vanko, G.; Mozolova, Z.; Hascik, S.; Chlpik, J.; Hotovy, I.; Rehacek, V.; Kostic, I. GaAs Based Micro-machined Thermal Converter for Gas Sensors. Sens. Actuators A Phys. 2008, 142, 147-152. [CrossRef]

29. Xu, P.; Cheng, Z.; Pan, Q.; Xu, J.; Xiang, Q.; Yu, W.; Chu, Y. High Aspect Ratio $\operatorname{In}_{2} \mathrm{O}_{3}$ Nanowires: Synthesis, Mechanism and $\mathrm{NO}_{2}$ Gas-sensing Properties. Sens. Actuators B Chem. 2008, 130, 802-808. [CrossRef] 
30. Inyawilert, K.; Channei, D.; Tamaekong, N.; Liewhiran, C.; Wisitsoraat, A.; Tuantranont, A.; Phanichphant, S. Pt-doped $\mathrm{In}_{2} \mathrm{O}_{3}$ Nanoparticles Prepared by Flame Spary Pyrolysis for $\mathrm{NO}_{2}$ Sensing. J. Nanopart. Res. 2016, 18, 40. [CrossRef]

31. Zhao, J.; Yang, T.; Liu, Y.; Wang, Z.; Li, X.; Sun, Y.; Du, Y.; Li, Y.; Lu, G. Enhancement of $\mathrm{NO}_{2}$ Gas Sensing Response Based on Ordered Mesoporous Fe-doped $\mathrm{In}_{2} \mathrm{O}_{3}$. Sens. Actuators B Chem. 2014, 191, 806-812. [CrossRef]

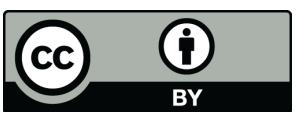

(C) 2019 by the authors. Licensee MDPI, Basel, Switzerland. This article is an open access article distributed under the terms and conditions of the Creative Commons Attribution (CC BY) license (http://creativecommons.org/licenses/by/4.0/). 